\title{
La negociación Mercosur-India: oportunidades comerciales para Uruguay
}

\author{
Mercosur-India negotiations: \\ Business opportunities for Uruguay
}

\author{
IGNACIO BARTESAGHI* \\ DEEPAK BHOJWANI*
}

Resumen: Recientemente comenzaron las negociaciones para profundizar el acuerdo entre el Mercado Común del Sur (Mercosur) e India, las cuales enfrentan dificultades naturales entre dos actores proteccionistas y con pocos tratados comerciales. Uruguay muestra potencialidades para ampliar su comercio en alimentos, que hoy enfrentan elevados aranceles y barreras no arancelarias. Por otra parte, India tiene ventajas en bienes industriales, muchos de los cuales no produce Uruguay pero sí sus principales socios en el Mercosur. Esta realidad adelanta que las negociaciones entre los dos actores no estarán exentas de dificultades.

Palabras clave: Mercosur; India; negociaciones; oportunidades comerciales; proteccionismo.

Abstract: A round of negotiations between Mercosur and India was recently launched to deepen the agreement in force. These negotiations will face the difficulties inherent with two actors who apply

Recepción: 9 de marzo de 2017. / Aceptación: 10 de julio de 2018.

*Universidad Católica del Uruguay, ibartesa@ucu.edu.uy; Latindia, bhojwani@ latindiaconsult.com 
highly protectionist policies and have negotiated few trade agreements. As part of these negotiations, Uruguay has the potential to expand trade in processed foods, which currently face high tariff levels and non-tariff barriers. On the other hand, India enjoys advantages in industrial goods, many of which are not manufactured within Uruguay but by its main partners in Mercosur. This reality implies that negotiations between the two actors will not be without difficulties.

Keywords: Mercosur; India; negotiations; trade opportunities; protectionism.

\section{Introducción}

El artículo se enmarca en las recientes negociaciones lideradas por la Presidencia pro tempore del Mercosur (en ese momento a cargo de Uruguay) para profundizar el Acuerdo de Preferencias Fijas vigente entre el bloque sudamericano e India, camino similar al que recientemente siguió Chile.

Dicha iniciativa se lanza en momentos en que el Mercosur cumple 25 años de historia y enfrenta enormes desafíos en un nuevo contexto internacional marcado por una histórica apertura comercial. Por otra parte, India se ha transformado lentamente en una economía emergente de relevancia global y su economía muestra tasas de crecimiento que superan las de China en los últimos años. La potencia asiática también enfrenta serios retos respecto a su apertura comercial, ya que ha firmado contados acuerdos comerciales.

El objetivo de este artículo es identificar los principales aspectos que deben tenerse en cuenta al emprender una negociación entre las dos partes. Para cumplirlo, luego de destacar la importancia de India como actor global y su relación con América Latina, se describen las características esenciales de la política comercial de India y el Mercosur, así como su estructura institucional en relación con las negociaciones y la evolución del comercio bilateral. 


\section{India y su relación con América Latina}

\section{Características de India}

El entorno empresarial de India ha mejorado en las últimas dos décadas debido a una apertura constante de su mercado a las importaciones extranjeras y a la implementación de reformas muy profundas (Mesquita, 2010, p. 1).

Además, se trata de un país que muestra tasas de crecimiento de su producto interno bruto (PIB) muy elevadas en los últimos años, lo que ha favorecido el aumento en el ingreso y la consolidación de una clase media que supera los 400 millones de personas (gráfica 1).

GrÁfICA 1. Crecimiento del PIB de India

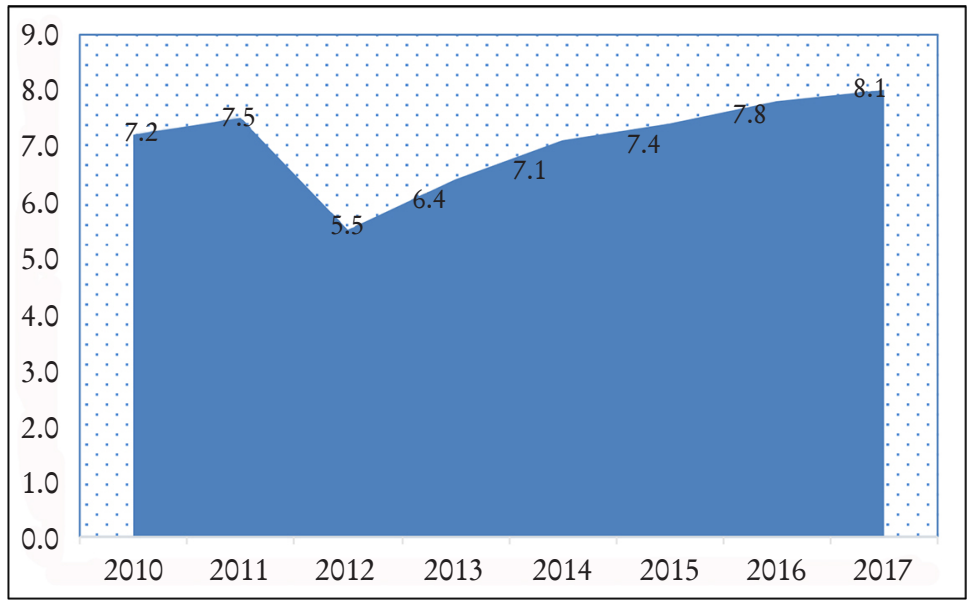

Fuente: elaboración propia con base en Banco Mundial, 2017.

Más allá de las robustas tasas de crecimiento, el país sigue mostrando una baja participación en el comercio internacional y ha suscrito muy pocos acuerdos comerciales, al aplicar hasta el presente un importante número de medidas proteccionistas 
que afectan el ingreso a dicho mercado. Cabe destacar que India posee una mayor participación en el comercio de servicios y una destacada posición en algunas subcategorías de otros servicios comerciales (Rosales y Kuwayama, 2007, p. 86).

GRÁFICA 2. Participación

de India en el comercio mundial de bienes

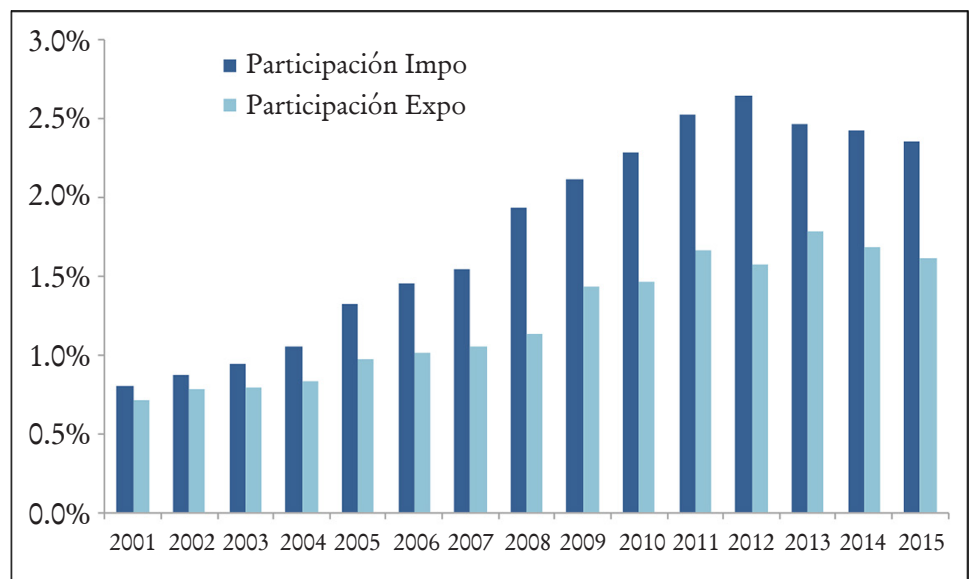

Fuente: elaboración propia con base en International Trade Centre, 2017a.

Las reformas emprendidas por India en los últimos años son de una enorme magnitud e impacto internacional (gráfica 2), especialmente si se tienen en cuenta su sistema de gobierno y otros factores como diversidad cultural y religiosa, etnias, territorio y población (Sistema Económico Latinoamericano y del Caribe, 2014, p. 13). Algunas se relacionan con sus reservas, el desarrollo de su mercado de valores, la inversión externa, las empresas indias globales de bienes y servicios, la importancia de la agricultura en aspectos como la reserva ganadera o la mano de obra agrícola (50\% del total), entre otros.

Se trata de un país que si bien mantiene cierto rezago en infraestructura (que se ve reflejado en indicadores de competitividad como el Doing Business y el World Economic Forum), 
cuenta con una importante red de ferrocarriles, carreteras, comunicaciones y puertos marítimos, así como con un desarrollo energético en sectores como gas, carbón y energía solar, nuclear y eólica (Bhojwani, 2014, pp. 33-46).

Las empresas indias también han aprendido a explorar y explotar los mercados extranjeros en su propio beneficio. Hoy, las industrias del automóvil, farmacéuticas, textiles, prendas de vestir, productos químicos y de ingeniería de India tienen una amplia y cada vez más profunda presencia en varios países del mundo. Destaca particularmente la industria del software, pues varias de las empresas más importantes a nivel global están en el país.

Más allá de su progresiva apertura, que se ha visto reflejada en una baja en sus aranceles, India continúa mostrando elevada protección arancelaria y no arancelaria en algunos sectores industriales y agrícolas. Esta realidad se complementa con una política comercial poco activa en cuanto a la firma de acuerdos comerciales más allá de los que posee con sus vecinos más próximos o las recientes negociaciones de mayor importancia que el país tiene abiertas con la Unión Europea y en el marco del Regional Comprehensive Economic Partnership (Kume, Piani y Miranda, 2005, pp. 1-4).

\section{La relación con América Latina}

Por razones tanto históricas como geográficas, las relaciones entre India y América Latina son muy recientes y tienen todavía gran potencial. De todas formas, desde hace tiempo ha habido algunos contactos culturales que progresivamente lograron un mayor conocimiento mutuo y que pueden ser una base para expandir la relación en otras áreas (Bhojwani, 2014, pp. 33-46).

Los cambios que se dieron internacionalmente desde la primera década del 2000 en cuanto a la importancia de las economías emergentes, permitieron un acercamiento gradual entre India y América Latina a partir del trato entre Brasil e India, formalizado incluso a través del Foro de Diálogo India, Brasil y Sudáfrica y posteriormente del grupo BRICs (Brasil, Rusia, 
India, China y Sudáfrica), instrumentos que fortalecieron las relaciones sur-sur (Stuenkel, 2010, pp. 290-304). De hecho, el intercambio entre el Mercosur e India tuvo el impulso de Brasil a través de la firma de un acuerdo comercial (parcial si se compara con los tratados de libre comercio clásicos) cuyo objetivo principal fue el componente geopolítico y no comercial, más allá de la evidente potencialidad económica entre ambos actores (Brat, 2005, p. 1). Más recientemente, India ha reforzado aún más su interés en América Latina debido al espacio ganado por China en la región, lo que de cierta forma ha impulsado una diplomacia un poco más agresiva para ocupar una posición más acorde con la importancia global de India (Kumar, 2010, pp. 10-13).

El comercio de India con América Latina aumentó a una tasa de más de 30\% anual desde inicios del siglo hasta 2013, fecha a partir de la cual hubo una desaceleración, por varias razones. La reciente reducción en el intercambio se ha debido a la caída de los precios de las materias primas, especialmente del petróleo crudo.

La canasta de exportaciones de India ha sido más diversa y resistente a los cambios del contexto internacional, ya que abarca principalmente manufacturas y servicios, como los vinculados con las tecnologías de la información. En el caso de las tecnologías de la información se ha producido una coincidencia fortuita de interés entre India y América Latina con las principales empresas indias de dicho sector, que emplea a más de 25000 técnicos locales en toda la región bajo el modelo de outsourcing, lo que permite atender el mercado de América Latina, pero también el de América del Norte. El avance de India en la industria de las tecnologías de la información permite identificar algunas complementariedades con América Latina, y con el Mercosur en particular, pero es necesario contar con acuerdos más profundos que no sólo incluyan disposiciones sobre bienes, sino que también incorporen un capítulo de servicios (Finquelievich, 2004, pp. 223-233).

América Latina necesita diversificar sus exportaciones de productos básicos y semielaborados. Asimismo, se pretende atraer la inversión no sólo a su economía extractiva, sino también a los sectores secundario y terciario. Las empresas indias 
son capaces de invertir en el extranjero, pero necesitan incentivos para preferir a América Latina sobre otras regiones. También hay resistencia debido a la falta de familiaridad con el entorno empresarial y jurídico, la distancia geográfica, el idioma y otras barreras. Es recomendable que los gobiernos de la región fomenten acciones informativas sobre las perspectivas en los mercados y las condiciones y los incentivos que se ofrecen a empresas extranjeras. Esta acción es muy bien recibida por los empresarios indios, que, a través de foros empresariales organizados por las principales cámaras del país asiático, muestran cada vez mayor interés en la región (Confederation of Indian Industry-Government of India, 2015, pp. 1-2).

Las negociaciones con India deben acelerarse a fin de identificar las prioridades de cada parte negociadora y luego hacer ofertas que atraigan a los empresarios al mercado potencial. El éxito inicial en estos trabajos serviría como disparador de una mayor colaboración, inversión y apertura progresiva de los mercados. América Latina tiene que disipar la imagen negativa que se ha difundido sobre las dificultades de hacer negocios en la región. En particular, la ley y el orden, las condiciones económicas precarias (especialmente las grandes deudas, que conducen a la volatilidad de la moneda), la corrupción e incluso la dificultad de la comunicación en inglés afectan la profundización de las relaciones, algunas falencias que, como es sabido, caracterizan a los países del Mercosur.

Los negociadores de América Latina necesitan identificar la experiencia local para navegar por la realidad india. El establecimiento oficial es difícil incluso para las embajadas locales. La distancia física hace que los viajes hacia y desde esa región sean complejos. La facilitación local puede ayudar en el proceso de identificar y aligerar el proceso de negociación que desde ya se imagina complicado.

La negociación entre India y el Mercosur debe tener un marcado foco en las barreras no arancelarias, ya que se trata de dos mercados muy proteccionistas. En el caso de India, sus preocupaciones se plantean en los procedimientos para el registro de formulaciones genéricas y de marcas, requisitos de contenido regional, registro de agroquímicos y controles fitosanitarios. Por otra parte, la relación de ese país con el Mer- 
cosur está marcada por los elevados costos logísticos, lo que naturalmente afecta la profundización de las relaciones comerciales.

La historia reciente muestra la importancia otorgada por India a la relación con Brasil (más allá de la relación que el país asiático tiene con Chile y comercialmente con Colombia), único país de América del Sur con el que mantiene una relación que va más allá de lo económico-comercial y que plantea posiciones comunes en temas de suma importancia para la gobernanza global. El impulso otorgado por Brasil a las negociaciones será clave para avanzar de forma definitiva hacia la ampliación de un acuerdo que, como se muestra, ha tenido escaso o nulo aprovechamiento (Bartesaghi, 2015, pp. 1-2: Roett, 2010, pp. 36-38).

\section{Introducción a la política comercial de India y el Mercosur}

Desde hace varias décadas, India trata de equilibrar el objetivo de promocionar sus exportaciones con la necesidad de abrir sus propios mercados a la competencia extranjera en el marco de las reglas de la Organización Mundial del Comercio y bilateralmente con países o bloques comerciales (Rosales y Kuwayama, 2007, p. 86), como la Asociación de Naciones del Sudeste Asiático, la Unión Europea, la Asociación Sudasiática para la Cooperación Regional y el Mercosur, entre otros. La mayoría de los acuerdos negociados por la potencia asiática no constituyen tratados de libre comercio. En los hechos, varios de los acuerdos son expresiones de intención que tienen por objetivo mejorar las condiciones de acceso para el comercio entre India y sus interlocutores.

Algunos foros a nivel burocrático (normalmente de secretario o viceministro) están configurados para este fin, como el Comité Económico y Comercial Conjunto entre India y Costa Rica en el marco del memorando de entendimiento firmado en 2013, o la Comisión Mixta de Cooperación para el Desarrollo de Negocios con Colombia constituida en 2010. Estos ámbitos podrían derivar en acuerdos comerciales como los que se tienen 
con el Mercosur y Chile, que son más profundos y en los que se fijan tarifas preferenciales o se eliminan aranceles. El acuerdo con Chile recientemente se amplió.

De cualquier forma, cabe aclarar que se trata de pactos muy limitados en términos tanto de su alcance (capítulos negociados) como de su cobertura (número de preferencias otorgadas). A modo de ejemplo, el acuerdo entre el Mercosur e India no supera las 500 líneas arancelarias por cada parte y muchos de los bienes incorporados a las preferencias ya estaban liberalizados en términos de nación más favorecida (lo que implica que no se otorgaron preferencias). Además, se trata de preferencias fijas, por lo que para dichos bienes no se definió un cronograma de desgravación arancelaria.

El Mercosur definió alcanzar un mercado común entre sus miembros con la previa conformación de una zona de libre comercio y una unión aduanera. Esto marcó la política exterior del bloque hasta el presente, ya que, debido a la decisión de conformar una unión aduanera, todos los miembros se comprometieron a seguir una política comercial común.

El bloque fue el instrumento mediante el cual los socios alcanzaron una apertura regional tras la eliminación de tarifas en gran parte del universo arancelario (algunos sectores, como el automotriz, fueron excluidos de la zona de libre comercio). Por otra parte, se aprobó un arancel externo común con considerables excepciones. Paralelamente, el bloque no logró avanzar en la armonización de normas aduaneras consideradas centrales para ser catalogado como unión aduanera (Bartesaghi, 2012, p. 30).

Los acuerdos comerciales del Mercosur estuvieron limitados a la región y se negociaron en el marco de la Asociación Latinoamericana de Integración; destacan los primeros, con Chile y Bolivia, con la Comunidad Andina, Perú y Cuba (este último muy limitado). Al igual que India, el Mercosur no cuenta con acuerdos con Estados Unidos ni con la Unión Europea (si bien ambos lo están negociando), ni con ningún país asiático. De extrazona sólo ha firmado acuerdos con Israel, Egipto, la Unión Aduanera del África del Sur) y Palestina, que en algunos casos no están vigentes. Así como ocurre con India, el Mercosur no ha suscrito acuerdos ambiciosos en términos normativos 
al no incorporar en su bloque ni en los acuerdos de extrazona las nuevas disciplinas comerciales.

\section{Las instituciones vinculadas a las negociaciones}

El Departamento de Comercio de India, que actualmente forma parte del Ministerio de Comercio e Industria, se encuentra bajo la órbita independiente del ministro de Estado. Aunque no es un ministerio, dicho departamento es independiente e informa directamente al primer ministro sobre las negociaciones comerciales en que tiene suma relevancia. Con el tiempo, bajo el sistema parlamentario indio, todos los acuerdos tendrán que ser aprobados por el Consejo de Ministros (lo mismo que las modificaciones).

El Consejo de Ministros selecciona un gabinete de gobierno que participará en las negociaciones comerciales, que normalmente incluye a aquellos ministros cuyos cargos son relevantes para el tema en cuestión. Por lo tanto, la reunión del gabinete para aprobar un acuerdo de libre comercio, presidida por el primer ministro, por lo general incluye al ministro de Comercio e Industria, al de Finanzas, al de Asuntos Exteriores, y a otros que se consideren importantes para el acuerdo en negociación.

Por debajo del nivel ministerial, como se comentó, la jerarquía burocrática que elabora y negocia los acuerdos en India está encabezada por el secretario de Comercio. Este oficial es normalmente un burócrata de carrera que dirige el Departamento de Comercio. Los otros funcionarios directamente involucrados son: el secretario adjunto a cargo de la División de Comercio Exterior (América Latina y el Caribe), el secretario adicional o adjunto a cargo de la División de Política Comercial, y otros oficiales que pueden estar a cargo de las divisiones que se ocupan de los productos básicos de interés para la negociación en particular del mencionado ministerio.

El Ministerio de Finanzas de India desempeña un papel crucial en estas negociaciones, ya que es la autoridad final en relación con la configuración de los límites de la tarifa acordada. También es responsable de los mecanismos de despacho de 
aduanas (a través de su Departamento de Ingresos) y participa en otros aspectos que inciden en tales negociaciones, incluidos los impuestos.

El Ministerio de Asuntos Exteriores también participa a través de las divisiones responsables de la estrategia económica y comercial del país, así como de las aportaciones políticas para tales negociaciones. Este ministerio, a través de sus embajadas y sus diplomáticos, proporciona información esencial sobre las prioridades y las condiciones de India en el país con el que se llevan a cabo las negociaciones.

Además de los ministerios descritos, hay varias autoridades cuya participación es esencial para el buen funcionamiento y la facilitación de los acuerdos económicos y comerciales negociados por India. Incluyen la Dirección de Aduanas e Impuestos; los organismos de control de los distintos ministerios, como la inspección de alimentos, que garantiza que las normas sanitarias y fitosanitarias se respeten debidamente; la Dirección General de Derechos Antidumping y Afines, responsables de llevar a cabo investigaciones y recomendar, cuando así lo exija (en virtud de la Ley del Arancel de Aduanas), el importe de los derechos antidumping o derechos compensatorios sobre artículos identificados con posibilidades de dañar la industria nacional. Cabe aclarar que el sector de negocios indio siempre es consultado y suele tenerse en cuenta su opinión.

En el caso del Mercosur, cuenta con presidencias pro tempore que duran seis meses y son asumidas por todos los miembros mediante rotación alfabética. Salvo designación en contrario, el país que tiene a su cargo la presidencia lleva adelante las obligaciones inherentes al desarrollo de la agenda interna y externa del bloque, lo que incluye la negociación de acuerdos comerciales.

Debido a la confección de un arancel externo común, todos los acuerdos impulsados por el Mercosur deben negociarse en conjunto, lo que implica instancias previas entre los miembros (en las negociaciones con la Unión Europea o la ampliación del acuerdo con India, Venezuela no forma parte de las negociaciones) para definir posiciones comunes y confeccionar una oferta Mercosur que se presenta de forma conjunta a la contraparte. Esta mecánica no implica que, en algunos casos, 
FiguRA 1. Autoridades indias involucradas en las negociaciones comerciales

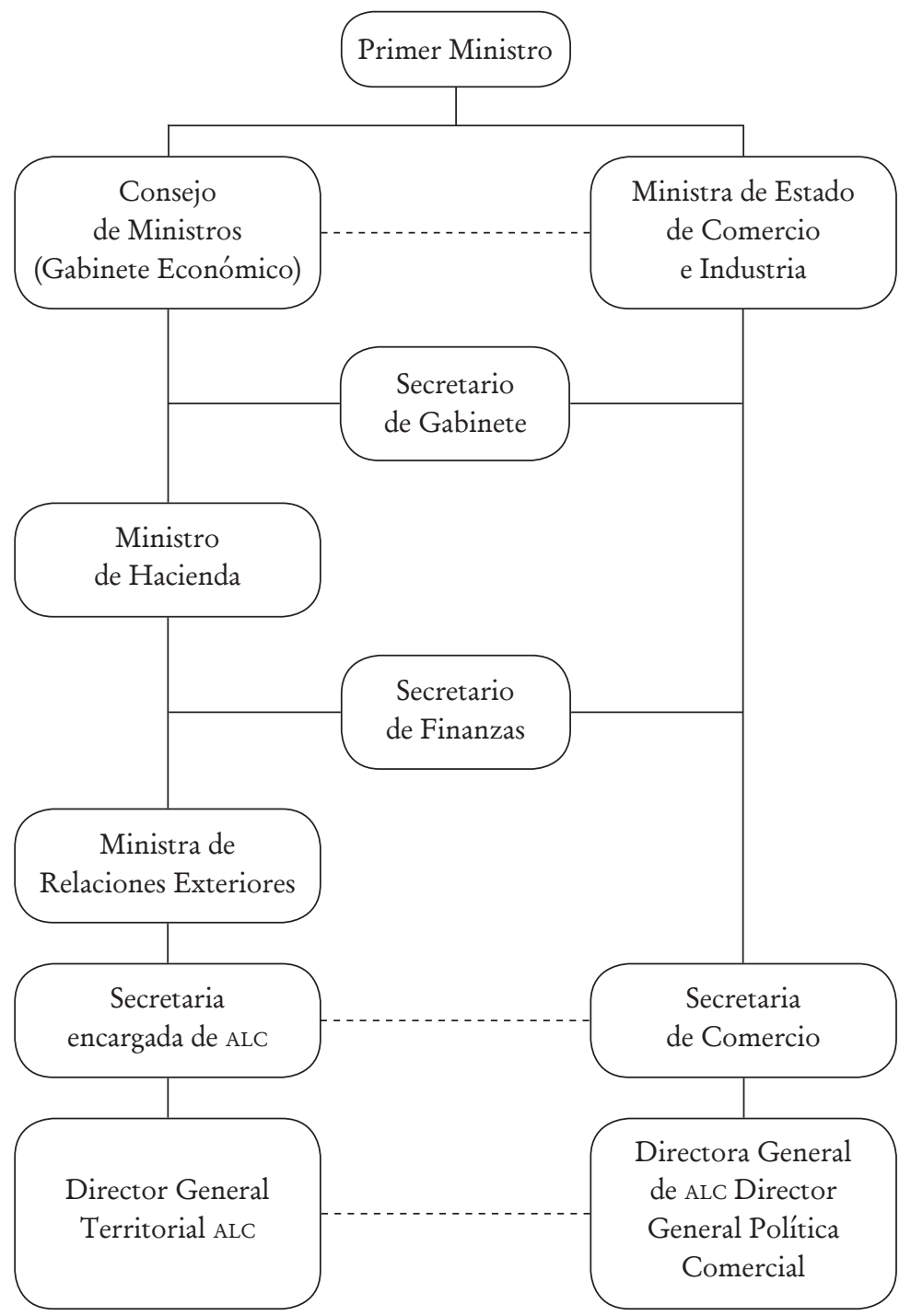

Fuente: elaboración propia. 
se hayan permitido diferencias puntuales en los cronogramas finales negociados (entre el Mercosur y la Comunidad Andina, por ejemplo). Cabe recordar que en una oportunidad el bloque fue flexible respecto a la negociación conjunta, ya que Uruguay logró suscribir un tratado de libre comercio con México de forma bilateral (previa firma de un acuerdo marco entre el Mercosur y México).

Independientemente del apoyo interministerial con que cuente cada miembro que tenga a su cargo la presidencia del bloque, estas presidencias están a cargo de las direcciones de Mercosur de las cancillerías, que incluso deben publicar las reuniones técnicas que se llevarán a cabo durante el semestre. La decisión de ampliar el acuerdo con India fue tomada en el marco de la presidencia de Uruguay y fue apoyada por el resto de los miembros (Venezuela no integra las negociaciones y no presentó objeción a la profundización de ese acuerdo), con especial liderazgo de Brasil. Durante la presidencia uruguaya se realizaron videoconferencias para definir los aspectos técnicos en que se desarrollaría la negociación (cobertura, profundidad y preferencias, entre otros aspectos) y se hicieron reuniones intraMercosur para la presentación de una primera oferta en bienes, lo que implica una apertura formal de las negociaciones entre las partes.

Recientemente, el bloque enfrentó una crisis por el traspaso de la presidencia pro tempore debido a la situación experimentada por Venezuela. Más allá de las dificultades que se tuvieron en este sentido, las negociaciones siguieron su curso en el marco de la presidencia a cargo de Argentina.

\section{Negociaciones entre el Mercosur e India}

Las negociaciones se remontan al acuerdo marco firmado el 17 de junio de 2003 en Asunción, Paraguay. El objetivo principal fue el establecimiento de condiciones y la definición de mecanismos para conformar, en dos etapas, una zona de libre comercio entre las partes. Este primer paso derivó en la firma del Acuerdo de Comercio Preferencial suscrito por las partes en Nueva Delhi, India, el 25 de enero de 2004. 
El acuerdo, que entró en vigor el 1 de junio de 2009 y fue notificado a la Organización Mundial del Comercio, tiene por principal objetivo ampliar y promover la expansión del comercio a través de la concesión de preferencias recíprocas. Respecto al alcance, se trata de un número muy bajo de concesiones arancelarias, que van de 10 a $100 \%$ para 450 y 452 líneas arancelarias por cada parte (Bartesaghi, 2010, p. 2).

De las 450 líneas arancelarias, India ha otorgado margen de preferencias de $10 \%$ a 93 productos, de $20 \%$ a 336 y de $100 \%$ a 21 mercaderías. Los principales sectores incluidos en la oferta de India son: carne y productos cárnicos, productos químicos inorgánicos, productos químicos orgánicos, colorantes y pigmentos, cueros y pieles, artículos de cuero, lana, hilo de algodón, vidrio y cristalería, artículos de hierro y acero, aparatos mecánicos y equipos eléctricos, ópticos, fotográficos y cinematográficos.

En el caso del Mercosur, el bloque ha ofrecido un margen de preferencias en un total de 452 líneas arancelarias, de las cuales 393 tienen un margen de 10\%, 45 de 20\% y 14 de 100\% respectivamente. Los principales grupos de productos incluidos en la oferta del bloque son: preparados alimenticios, productos químicos orgánicos, productos farmacéuticos, aceites esenciales, plásticos y sus manufacturas, caucho y productos de caucho, herramientas y utensilios, artículos de maquinaria, y maquinaria eléctrica y equipos.

Naturalmente, hay un margen sustancial para que el Mercosur e India exploren las complementariedades y se beneficien de un aumento del comercio bilateral. El bloque sudamericano se beneficiará cada vez en mayor medida de las industrias globales de India en software y farmacéuticos. Por otra parte, India puede asegurarse el suministro de petróleo y otras necesidades de recursos naturales mediante la asociación con países del Mercosur.

Venezuela se adhirió al Mercosur como quinto miembro el 31 de julio de 2012, mientras que Bolivia sigue el mismo camino. Desde la visión de India, la incorporación de estos dos miembros ofrece nuevas posibilidades para su mercado en determinados productos de importancia para el país asiático. Cabe recordar que Venezuela fue el mayor socio comercial de 
India en la región de América Latina durante 2014-2015 y el principal producto de importación fue el petróleo, que explica cerca de $98 \%$ del total del comercio de India con ese país.

A través del Foro de Diálogo India, Brasil y Sudáfrica, espacio que vincula a India con Brasil y Sudáfrica, se acordó la ampliación del acuerdo e incluso se barajó la posibilidad de hacerlo conjuntamente con el acuerdo que el Mercosur tiene con la Unión Aduanera del África del Sur, lo que después se descartó. La primera reunión del Comité de Administración Conjunta entre India y el Mercosur se llevó a cabo en noviembre de 2009 en Uruguay para discutir los diversos aspectos de la ejecución y la ampliación del acuerdo.

El segundo encuentro para la expansión del acuerdo se celebró el 16 de junio de 2010 en Nueva Delhi, donde ambas partes intercambiaron sus respectivas listas que incorporaron 3690 líneas arancelarias de India (3111 productos ofertados inicialmente, seguidos de una lista suplementaria de 589 bienes) y 1287 líneas del Mercosur. La lista suplementaria de este último nunca fue presentada. Ambas partes coincidieron en que hay una necesidad urgente de aumentar significativamente el número de productos del acuerdo vigente para cubrir una mayor parte del comercio bilateral.

En 2016, a impulso de la presidencia pro tempore de Uruguay y con apoyo de los demás miembros (especialmente Brasil), se iniciaron las negociaciones para ampliar el acuerdo vigente, que si bien incluirá un mayor número de productos, estará muy por debajo de la cobertura arancelaria de los tratados negociados internacionalmente, tanto en términos arancelarios como en las disciplinas incorporadas.

Las relaciones entre el Mercosur e India muestran algunos componentes centrales, como la relevancia otorgada a la energía dado que el bloque sudamericano es un importante proveedor, la importancia de la agricultura, la posible complementariedad en el sector farmacéutico y las tecnologías de la información, así como posibles socios en la agenda global y balance de poder respecto a la relación que los dos actores poseen con China (Tuchman y Dukkipati, 2010, pp. 1-3). Otros estudios identifican potencialidades específicas en el sector de etanol e industrias creativas, lo que demuestra un amplio margen de crecimiento 
en sectores que van más allá de los acuerdos vigentes o negociados (United Nations Conference on Trade and Development, 2014, pp. 19-21).

\section{Caracterización del comercio entre Uruguay e India ${ }^{1}$}

El comercio de bienes entre Uruguay e India se encuentra muy por debajo de su potencial. Como se observa en la gráfica 3, las exportaciones uruguayas hacia India alcanzaron los USD 14.1 millones en 2015, una suma muy insignificante si se tiene en cuenta el tamaño del mercado indio. Por otra parte, las importaciones superaron los USD 250 millones, lo que resulta en un abultado déficit comercial del país sudamericano respecto a India (no es la situación presentada por el Mercosur). En cuanto al dinamismo del comercio exterior, entre 1999 y 2015 aumentó a un promedio anual de $20 \%$, con un crecimiento en las exportaciones algo mayor que las importaciones.

Las exportaciones de Uruguay con destino a India mostraron un periodo de crecimiento ininterrumpido desde 2006 hasta 2011, fecha en que se alcanzó el pico máximo de colocaciones en dicho mercado. A partir de ese año, las exportaciones disminuyeron hasta alcanzar los mismos niveles de 2010.

Si bien el bajo flujo comercial con India puede significar a priori un impedimento para la preferencia otorgada al acuerdo, dicho análisis debe realizarse teniendo en cuenta la potencialidad futura, la complementariedad comercial en algunos sectores y el cada vez más importante papel de India en las inversiones de Uruguay y el Mercosur (en este último caso, con un interesante nivel de asociatividad empresarial, lo que es claro en el caso de Brasil). Naturalmente, no se podrá desconocer la importancia de este país en el escenario global, su gran mercado y el impacto que en el entorno de negocios están teniendo las reformas internas llevadas adelante por el gobierno.

${ }^{1} \mathrm{La}$ información estadística no incluye las operaciones desde zonas francas y a través de éstas. De cualquier forma, India no importa soja ni pasta de celulosa de Uruguay, los dos productos de mayor importancia comercializados desde y a través de zonas francas instaladas en el país. 


\section{GRÁfICA 3. Comercio bilateral Uruguay-India (en millones de USD)}

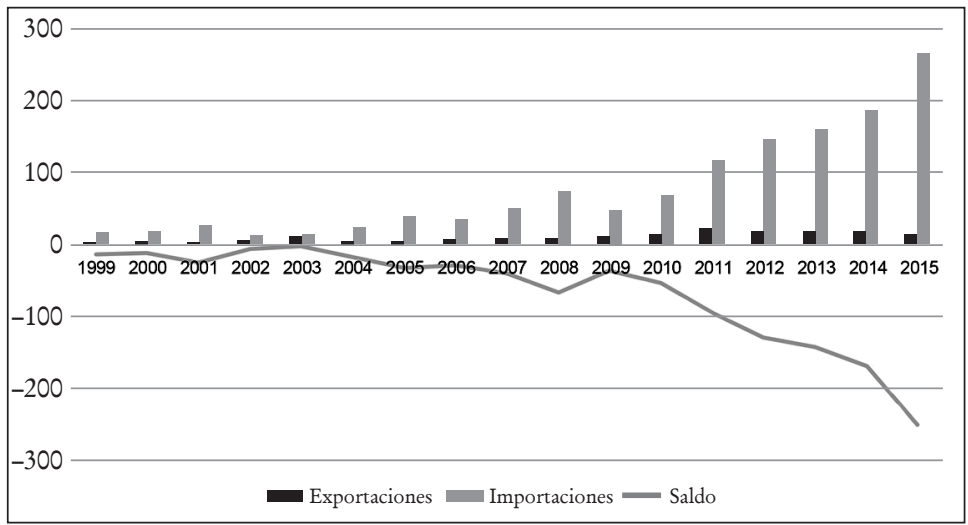

Fuente: elaboración propia con base en SmartDATA, 2017.

GRÁFICA 4. Exportaciones de Uruguay con destino a India (en millones de USD)

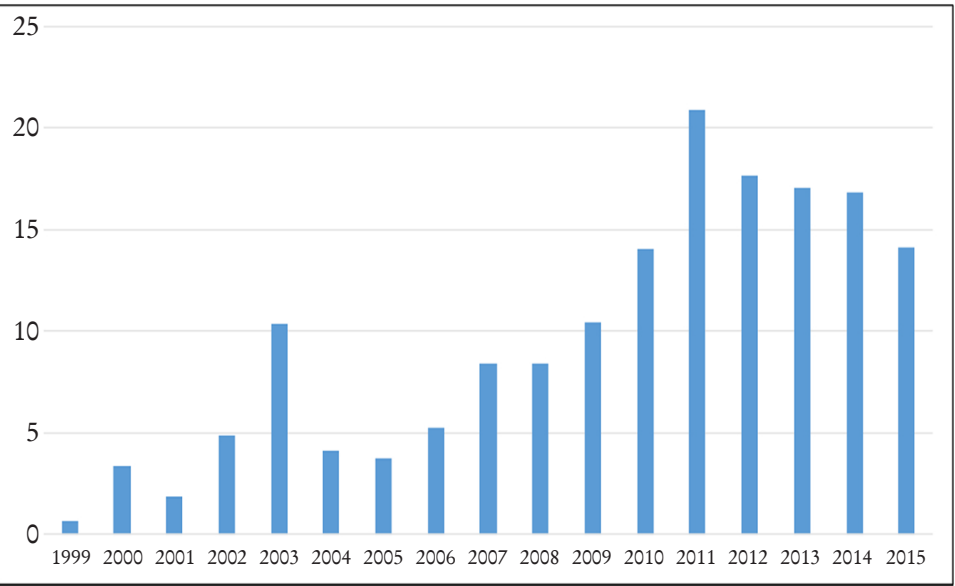

Fuente: elaboración propia con base en SmartDATA, 2017. 
En el caso de Uruguay, además de contar con un muy bajo nivel de exportaciones destinadas a dicho país, la concentración de productos es muy elevada. De hecho, cerca de $70 \%$ de lo colocado por el país en 2015 correspondió a ventas de lana.

En el cuadro 1 se observa el escaso número de productos colocados por Uruguay en India, los cuales superaron las exportaciones por una suma mayor a los USD 300000 , en promedio, en el periodo 1999-2015. Ahora bien, por otro lado, podría destacarse como positivo el que se identifiquen nuevas corrientes de exportación en comparación con el año 1999, como la madera y los productos lácteos.

CuAdro 1. Exportaciones de Uruguay a India por producto

\begin{tabular}{cc}
\hline Producto & $\begin{array}{c}\text { Exportaciones. } \\
\text { Promedio 1999-2015 }\end{array}$ \\
\hline Lana & $>$ USD 1 millón \\
Madera & $>$ USD 500 mil \\
Cueros y pieles & \\
Leche y productos lácteos & $>$ USD 300 mil \\
\hline
\end{tabular}

Fuente: elaboración propia con base en SmartDATA, 2017.

Respecto a las empresas exportadoras, se repite lo mismo que en bienes, pues son pocas las que exportan a India y el número alcanzado en 2015 está por debajo de los máximos históricos en que 51 empresas lograron exportar a dicho mercado. En cuanto a la concentración, en 2015 tan sólo 10 empresas explicaron más de $85 \%$ de lo colocado por el país en India, si bien debe destacarse que se trata de una concentración de 10 puntos más baja que la registrada en 1999 .

El relevamiento de las condiciones de acceso (considerando en esta primera instancia las arancelarias) que enfrentan las principales colocaciones de Uruguay en India confirmarían las restricciones que enfrenta el país para acceder a dicho mer- 
cado. En los hechos, si se computa $97 \%$ de las colocaciones uruguayas en India, correspondientes a 2015, se confirma el nulo o escaso impacto del acuerdo comercial anteriormente mencionado. En el cuadro 2 se presentan las condiciones de acceso para las 22 subpartidas exportadas (seis dígitos de la nomenclatura); se indica la importancia que dicho rubro tiene en las colocaciones totales de Uruguay y en las importaciones totales de India, y cuál es el flujo de exportación actual entre las partes.

Las únicas preferencias identificadas se dan en el marco del Sistema Global de Preferencias Comerciales entre países en desarrollo, mientras que el resto de los bienes exportados por Uruguay no tiene beneficios arancelarios para el acceso a India. Si se computan las preferencias comentadas - para lo cual se convirtieron los aranceles específicos en ad valorem-y se considera el peor escenario de acceso en el caso de las cuotas o aperturas a más dígitos del Sistema Armonizado, las colocaciones uruguayas en India enfrentan un arancel promedio de $17 \%$, guarismo muy elevado que indicaría la importancia de mejorar el acceso a dichos mercados de los bienes actualmente colocados, pero también de aquellos en que hay posibilidades de generar nuevas corrientes comerciales.

En referencia a las potencialidades comerciales, en el comercio actual, Uruguay ya es un proveedor de importancia en el caso de la lana (si bien en algunos rubros las corrientes podrían aumentar y en el marco de un acuerdo se podrían superar algunas restricciones de acceso que enfrenta este sector). A su vez, las estadísticas indicarían la potencialidad de colocar madera y lácteos en mayor volumen. Respecto a estos dos productos, la madera enfrenta un arancel no muy elevado (5\%), pero en el caso de los lácteos se trata de un sector muy protegido (contingentes) y con normas sanitarias y certificaciones alimentarias muy restrictivas.

En el caso de las importaciones de Uruguay desde India, es clara la mayor diversificación comercial y la colocación de productos industriales de alta tecnología del país asiático. Esta realidad llevaría a definir como complementario el comercio entre Uruguay e India, lo que a priori favorecería la suscripción de un acuerdo comercial y traería aparejados beneficios para las dos partes. Por otro lado, debe tenerse en cuenta que 


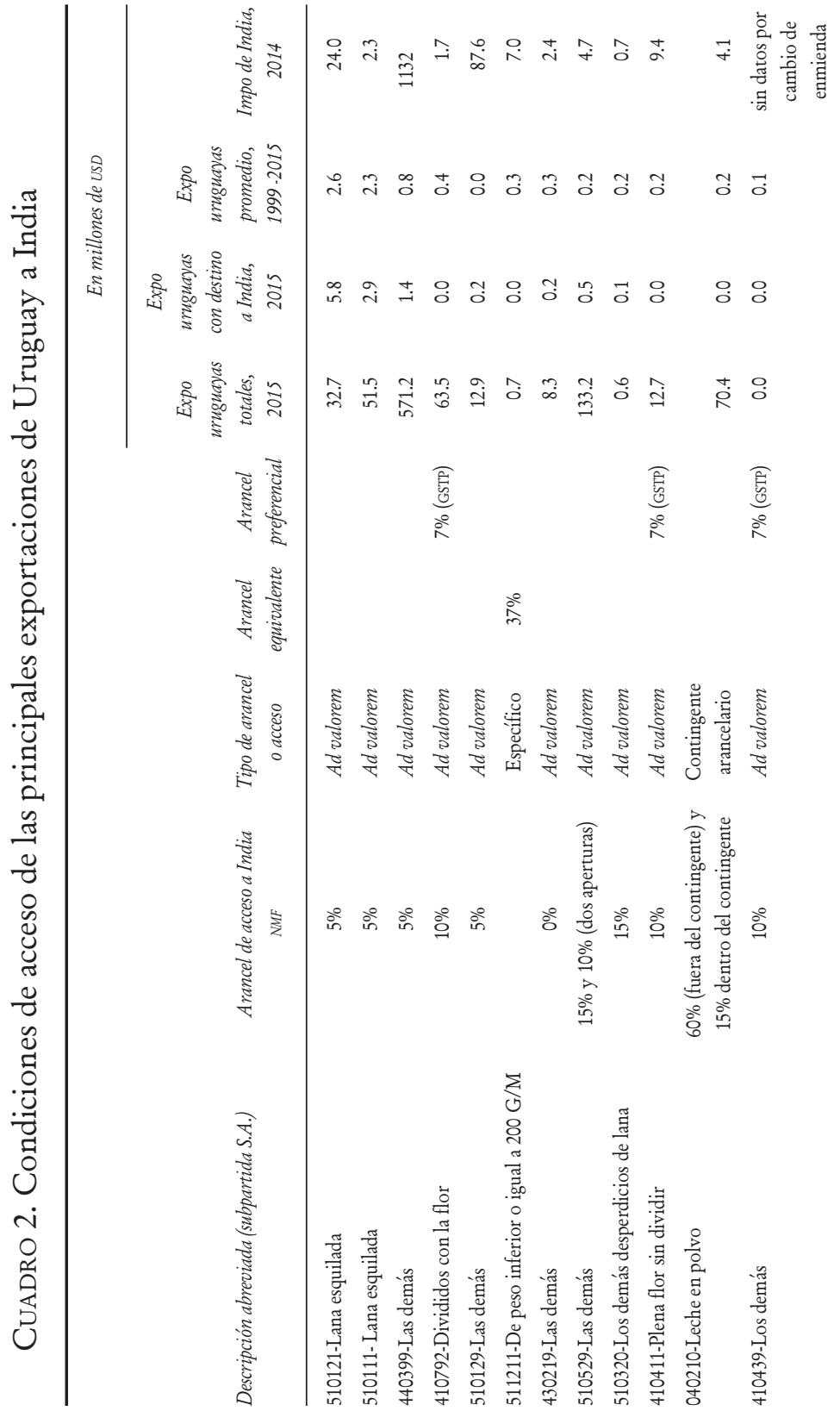




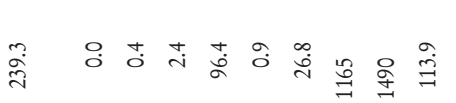

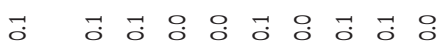

$$
\begin{aligned}
& \text { 웅 웅 융 }
\end{aligned}
$$

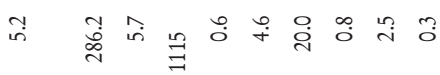

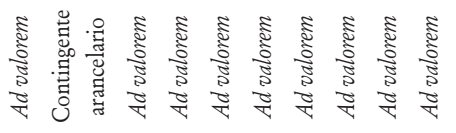

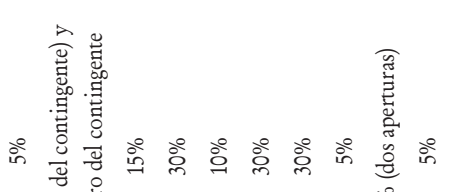

$$
\begin{aligned}
& \text { 造 } \\
& \text { ㅇํㅇ ㅇํํ } \\
& \text { 氙 }
\end{aligned}
$$

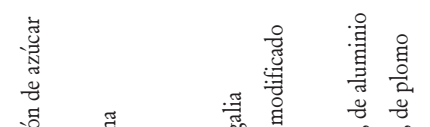

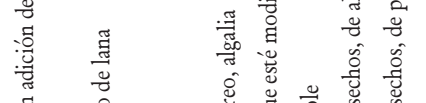

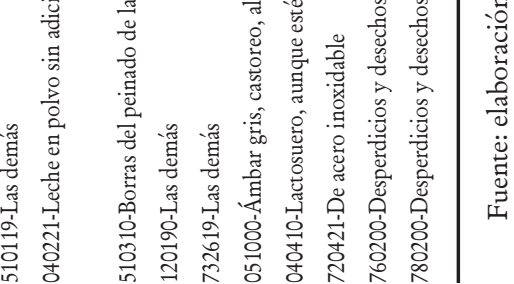


esta realidad cambia sustancialmente con la incorporación al análisis de Brasil y Argentina, dado que dichos países protegen sus industrias nacionales con elevados aranceles y otras medidas no arancelarias.

Si se computan las diferencias en las participaciones de los bienes importados desde India por Uruguay entre 1999-2015, son notorios los cambios en la estructura exportadora de India, ya que este país aumentó notablemente su importancia como proveedor de máquinas y aparatos eléctricos, así como de plásticos, en contrapartida con otros sectores industriales de menor contenido tecnológico, como textiles, vestimenta y químicos. Así como ha ocurrido con otros mercados asiáticos en los últimos años, India ha refinado su industria exportadora.

En 2015, los cuatro principales productos importados por Uruguay desde India fueron máquinas y aparatos eléctricos, vehículos automóviles y sus partes, productos químicos y plásticos, que representaron cerca de $80 \%$ del total. En esos bienes, el arancel externo del Mercosur es elevado, si bien hay algunas excepciones en el caso de Uruguay, y tienen que ver con el régimen de bienes de capital e informática, con el arancel externo común o las adquisiciones realizadas a través del régimen de admisión temporaria que, como se observa, es intensivamente utilizado en el caso de India y explica $23 \%$ de las importaciones totales en el año 2015 (materias primas o insumos utilizados para productos que necesariamente deben ser exportados en un periodo determinado).

Los aranceles en algunos productos de interés para India en el mercado sudamericano, así como los aranceles de India en los bienes agrícolas de mayor interés para el bloque (la tasa promedio de India en productos agrícolas asciende a 33.4\%; World Trade Organization, 2017), adelantan las dificultades que se presentarán en la negociación de pretender avanzar conjuntamente con todos los socios del Mercosur.

El caso de Uruguay es distinto, ya que gran parte de los bienes importados por India no se producen en el país. Cabe destacar que sí podrían presentarse algunas dificultades en vestimenta, químicos y plásticos que justificarían contemplaciones en la apertura. Podrían surgir algunas posiciones defensivas en el sector de medicamentos, si bien ya se observa complementarie- 
dad con India, que, como es sabido, es gran exportador de medicamentos.

Así como ocurre en la diversificación de productos, en las importaciones desde India el número de empresas involucradas es mucho mayor y muestra una tendencia clara de crecimiento. Cada vez más empresarios locales se benefician de los negocios con India en bienes muy variados y muchos de ellos no producidos en el país. La competencia en este sentido tiene mayores efectos en el comercio intrarregional y en las importaciones de otros orígenes, como China, Estados Unidos y Europa, pero no necesariamente en la industria nacional.

En cuanto al comercio potencial entre Uruguay e India, ${ }^{2}$ en el cuadro 3 se presentan los bienes que superan niveles de potencialidad de USD 50 millones y en los primeros lugares se identifican productos de alto contenido tecnológico (excepto el petróleo), sector en el que, como se comentó, India es cada vez más competitivo internacionalmente.

Considerando el arancel que enfrentaría India en Uruguay en productos identificados con mayor potencialidad (más de USD 50 millones), en el cuadro 4 se observa que la protección definida por el Mercosur para dichos bienes es elevada. En el caso de Uruguay hay algunas diferencias por los regímenes especiales de importación aplicados por dicho país, como los bienes de informática y telecomunicaciones o la lista de excepciones al arancel externo común. Las diferencias arancelarias presentadas entre Uruguay y el resto de los miembros del bloque (en particular Brasil y Argentina) confirman que el país tiene un mayor margen para negociar un acuerdo con India.

Al analizar la potencialidad de Uruguay en India en términos de importaciones (mayores a los USD 20 millones), también se observan, en el cuadro 5, niveles arancelarios elevados para el acceso a India, que en algunos casos supera el 100\%. El análisis adelanta parte de las sensibilidades que se presentarán en una negociación que vincula a dos actores ciertamente proteccionistas en su política comercial. Paralelamente, debe tenerse en cuenta que ni India ni el Mercosur han sido muy activos en la firma de acuerdos comerciales, y en los dos casos hay un rezago

\footnotetext{
${ }^{2}$ Procesamiento realizado con base en datos estadísticos informados por India.
} 


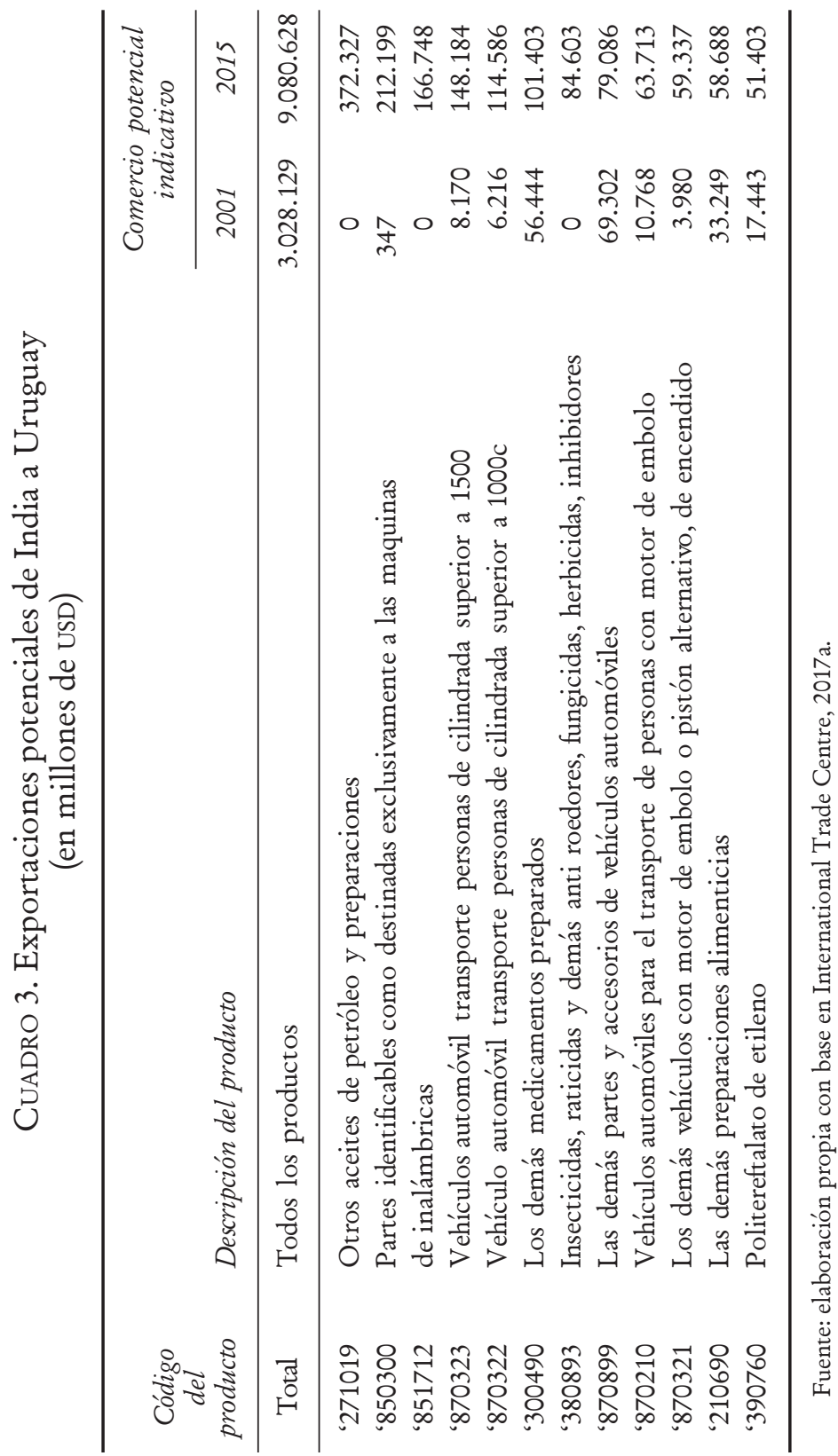


CuAdro 4. Arancel enfrentado por India en Uruguay (universo de productos con potencialidad)

\begin{tabular}{ccc}
\hline & \multicolumn{2}{c}{ Aranceles en porcentajes* } \\
\cline { 2 - 3 } Subpartida & TGA (Uruguay) & AEC (Mercosur) \\
\hline '850300 & 14 & 14 \\
'851712 & 2 & 20 \\
'870323 870322 & 23 & 23 \\
300490 & 23 & 23 \\
'380893 & 14 & 14 \\
'870899 & 14 & 14 \\
'870210 & 18 & 18 \\
'870321 & 6 & 20 \\
'210690 & 23 & 23 \\
'390760 & 18 & 18 \\
Promedio & 0 & 14 \\
\end{tabular}

* En el caso de las aperturas se consideró el nivel arancelario más elevado.

Fuente: elaboración propia con base en International Trade Centre, 2017b; Asociación Latinoamericana de Integración, 2017, y SmartDATA, 2017.

considerable en los beneficios de acceso e incorporación de las nuevas disciplinas comerciales.

\section{Conclusiones y recomendaciones}

Dos realidades diferentes motivan el reciente acercamiento entre el Mercosur e India: el escaso aprovechamiento del acuerdo vigente por parte de los empresarios y la potencialidad de aumentar los flujos comerciales en bienes.

El comercio actual entre Uruguay e India es todavía insignificante en el caso de las exportaciones de bienes, pero creciente y ya de cierta consideración en las importaciones. Si se atiende a las condiciones de acceso de Uruguay en India, los exportadores enfrentan en algunos casos elevados niveles arancelarios e incluso contingentes. 


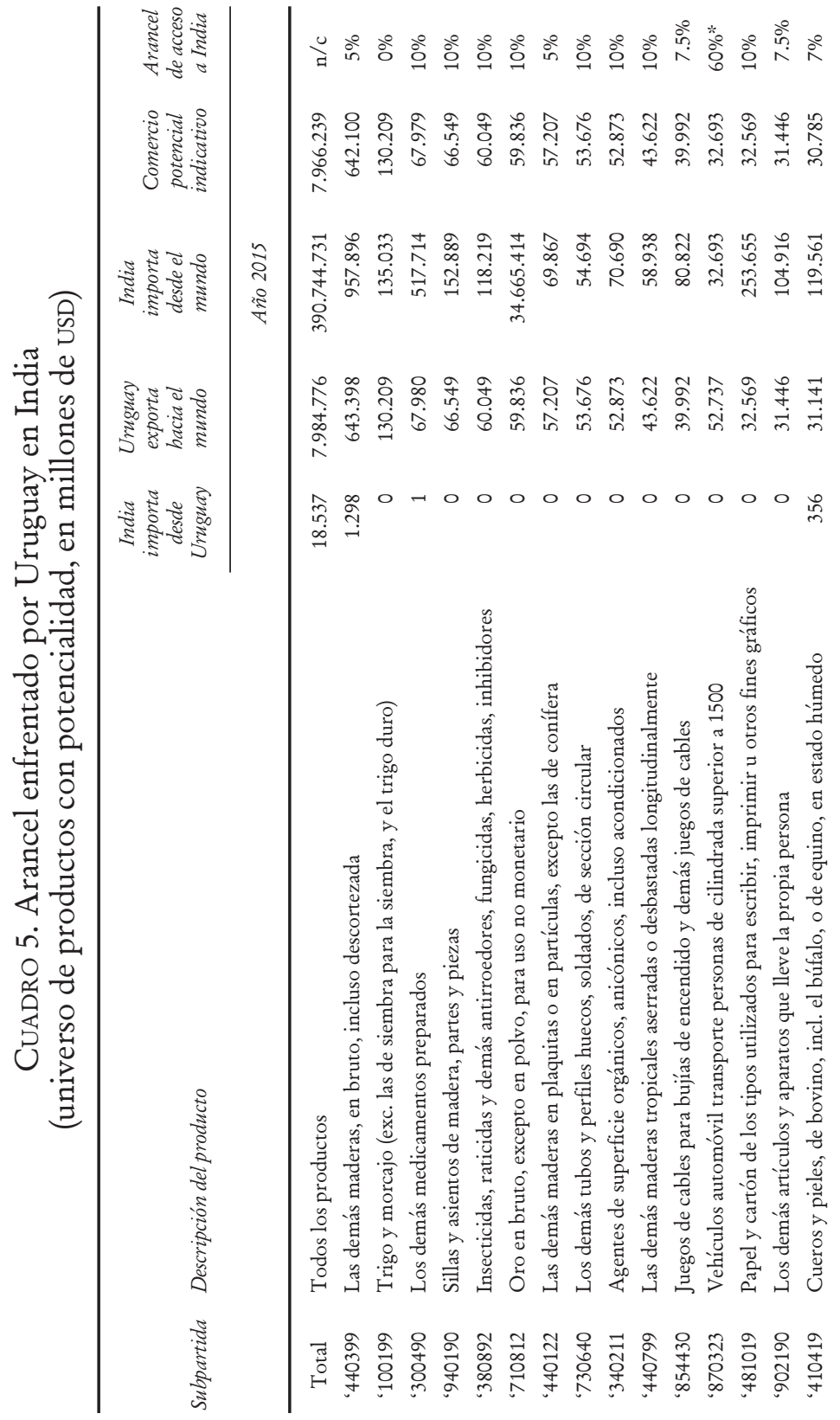




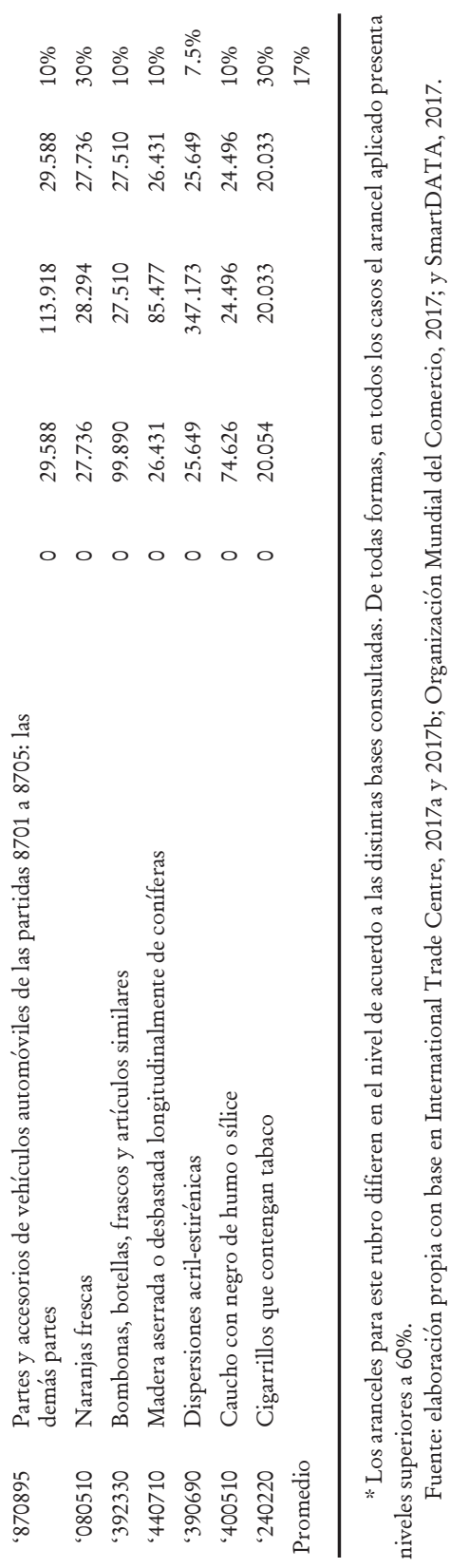

https://dx.doi.org/10.24201/eaa.v54i2.2310 
Las restricciones arancelarias aumentan considerablemente si se incorporan al análisis las exportaciones potenciales de Uruguay a India, rubro en que el país podría ver mejorado el acceso (no sólo en la baja o eliminación de los aranceles, sino también en la definición de normas técnicas y medidas sanitarias). Para el Mercosur, los resultados muestran similitud con el caso uruguayo, pero incluso con mayores oportunidades para Brasil y Argentina debido a la posibilidad de colocar alimentos procesados o algunos bienes industriales.

En el caso de las importaciones desde India, muchos de los bienes llegan en el marco del régimen de admisión temporaria, de regímenes especiales de importación o no se producen localmente. En otros casos, sí hay sensibilidades que podrían contemplarse en un acuerdo de las características del negociado, donde el universo de productos incluidos es relativamente bajo. De replicar el análisis en todo el Mercosur, la situación se vuelve compleja en relación con la competencia de India en las industrias brasileña y argentina en sectores en los que el país asiático ha ganado competitividad en los últimos años.

Más allá de las potencialidades señaladas, se debe reconocer que las negociaciones para ampliar el acuerdo no estarán exentas de dificultades. Son países muy proteccionistas que no han avanzado en la firma de acuerdos profundos ni de importancia económica en los últimos años, por lo que muestran un considerable rezago en términos de apertura de mercados y de reformas normativas vinculadas a los llamados nuevos temas del comercio mundial.

Para superar dichas restricciones, será necesario mostrar voluntad política y firmeza al defender los beneficios comerciales que derivarán de la ampliación del acuerdo. Asimismo, debido a las diferencias en las estructuras productivas entre los países del Mercosur, se recomienda contemplar flexibilidades que permitan negociaciones bilaterales en el caso de países del bloque que estén en condiciones de presentar una oferta algo más ambiciosa a India en el sector industrial, apostando como contrapartida al aumento de la cobertura de productos y el acceso a alimentos preparados con potencialidad de ser exportados a aquel país. 
Dirección institucional de los autores:

Universidad Católica del Uruguay

Av. 8 de Octubre 2738

11600 Montevideo, Uruguay

Latindia

8B, Edificio D1, The Hibiscus, Sector 50

Gurgaon-Haryana

122002 India

\section{Referencias}

Asociación Latinoamericana de Integración. (2017). Sistema de Información de Comercio Exterior. Información sobre aranceles vigentes, gravámenes y condiciones especiales [base de datos]. Recuperado de http://consultawebv2.aladi.org/sicoexV2/jsfAranceles/ arancel_vigente_menugroup.seam

Banco Mundial. (2017). India [base de datos]. Recuperado de https:// datos.bancomundial.org/pais/india? view $=$ chart

Bartesaghi, I. (2010). Acuerdo preferencial de comercio entre el Mercosur y la República de la India. Documento interno. Montevideo: Cámara de Industrias del Uruguay. Recuperado de http://www. ciu.com.uy/innovaportal/file/429/1/mercosur---india.pdf

BARTESAGHI, I. (2012). Las uniones aduaneras: ¿Modelo de integración adecuado para los países de la región? Montevideo: Universidad Católica del Uruguay. Recuperado de https://www.ucu.edu.uy/ sites/default/files/pdf/2015/Las_uniones_aduaneras.pdf

BARTESAGHI, I. (2015). India y América Latina: relaciones estratégicas en un nuevo contexto económico. Anuario de la Integración Regional de América Latina y el Gran Caribe, (11), 75-89. Recuperado de http://www.cries.org/wp-content/uploads/2016/02/05Bartesaghi.pdf

BHoJwANI, D. (2014). India and Latin America: Looking ahead. India Quarterly, 70(1), 33-46. https://dx.doi.org/10.1177/0974928413 511764

BRAT, M. (2005). India and Mercosur: Boosting trade through regionalism. (IBSA Briefing paper). CUTS Centre for International Trade, Economics \& Environment. Recuperado de http://www.cutscitee.org/PDF/IBSA-1-India-Mercosur.pdf 
Confederation of Indian Industry-Government of India. (2015). $6^{\text {th }}$ India-Latin America \& Caribbean conclave. Strengthening IndiaLAC business ties: Align; integrate; invest; engage; explore. A Report. Recuperado de http://www.human.ula.ve/catedralibreindia/ documentos/noticias/india_lac_report.pdf

Finquelievich, S. (2004). Las Tic en la cooperación Sur-Sur: el acuerdo de libre comercio entre la India y el Mercosur. Revista Iberoamericana de Ciencia, Tecnología y Sociedad, 1(3), 223-233. Recuperado de http://www.revistacts.net/files/Volumen\%20 1\%20-\%20N\%C3\%BAmero\%203/foro01.pdf

International Trade Centre. (2017a). Trade Map [base de datos]. Recuperado de https://www.trademap.org/Index.aspx?lang =es International Trade Centre. (2017b). Market Access Map [base de datos]. Recuperado de https://www.macmap.org

KumAR, R. (2010). India expanding relations with Latin America and Caribbean. The extraordinary and plenipotentiary diplomatist-plus, 10-13. Recuperado de http://hispanicindia.com/wp-content/ uploads/2014/08/Expanding_India_Latin_America_C_relations.pdf

Kume, H., Piani, G. y Miranda, P. (2005). India-Mercosul:perspectivas de um acordo de preferências comerciais. (Texto para discusión núm. 1120). Instituto de Pesquisa Econômica Aplicada. Recuperado de http://www.ipea.gov.br/agencia/images/stories/ PDFs/TDs/td 1120.pdf

Mesquita, M. (Coord.). (2010). India: Latin America's next big thing? (Special Report of Integration and Trade). Nueva York, NY: Inter-American Development Bank. Recuperado de http://publications.iadb.org/bitstream/handle/11319/413/India\%3a\%20 Latin\%20America\%C2\%BFs\%20Next\%20Big\%20Thing\%3f. pdf?sequence $=1$

Organización Mundial del Comercio. (2017). Perfiles arancelarios [base de datos]. Recuperado de https://www.wto.org/spanish/ res_s/statis_s/tariff_profiles_list_s.htm

Roett, $\bar{R}$. (2010). Brazil and India: $\bar{A}$ deepening relationship. The Brazilian Economy, 2(5), 36-38. Recuperado de http://bibliotecadigital.fgv.br/ojs/index.php/be/article/view/23214

Rosales, O. y Kuwayama, M. (2007). América Latina al encuentro de China e India: perspectivas y desafíos en comercio e inversión. Revista de la CEPAL, (93), 85-108. Recuperado de https:// repositorio.cepal.org/handle/11362/11224

Sistema Económico Latinoamericano y del Caribe. (2014). Las relaciones de América Latina y el Caribe con India: una ventana de 
oportunidad. (SP/RRRECALCPIA/DT 2-14). Recuperado de http://www.sela.org/media/264842/t023600006048-0-dt_2-14_ relacion_alc-india.pdf

SmartDATA. (2017). Uruguay Comercia [base de datos]. Recuperado de http://uruguaycomercia.com.uy/uchome.aspx

Stuenkel, O. (2010). The case for stronger Brazil-India relations. Indian Foreign Affairs Journal, 5(3), 290-304. Recuperado de http://freepdfhosting.com/b5e5796ed9.pdf

Tuchman, R. y Dukkipati, U. (2010). A role for India in Latin America's development. South Asia Monitor, (146). Recuperado de https://csis-prod.s3.amazonaws.com/s3fs-public/legacy_files/files/publication/sam 146.pdf

United Nations Conference on Trade and Development. (2004). Regionalism and South-South cooperation: The case of Mercosur and India. (TD $[\mathrm{XI}] / \mathrm{BP} / 11$, Eleventh session, São Paulo, 13-18 June 2004). Recuperado de http://unctad.org/en/Docs/tdxibpd11_en.pdf

World Trade Organization. (2017). India [Country profile]. Recuperado de http://stat.wto.org/CountryProfile/WSDBCountryPFView .aspx ? Language $=$ S\&Country $=$ IN 
